\title{
LÍNGUA INGLESA E IDEOLOGIA
}

\author{
EdMUndo NARRACCI GASPARINI*
}

\section{RESUMO}

Este artigo apresenta os resultados de uma investigação amparada na Análise do Discurso articulada por Michel Pêcheux, na qual foram analisados depoimentos sobre a língua inglesa escritos por alunos do curso de Letras da Universidade Federal de São João del-Rei. A investigaçáo tinha o objetivo de identificar as representaçôes acerca da língua inglesa que se constituíram na materialidade linguística dos depoimentos. Ademais, busca estabelecer possíveis consequências da abordagem da ideologia como "fantasia social" para os resultados da referida pesquisa e para a teoria da Análise do Discurso.

Palavras-Chave: língua inglesa, ideologia, fantasia.

\section{English as a foreign language and ideology}

\section{Abstract}

This article presents the results of an investigation based upon Michel Pecheux's Discourse Analysis whose objective was to identify the representations concerning English as a foreign language which constituted the written discourse of undergraduate students of Languages at Universidade Federal de São Joáo del-Rei. This article tries to evaluate the consequences of approaching ideology as "social fantasy" both to the results of the investigation presented here and to the theory of Discourse Analysis.

KEY wORDs: English as foreign language, ideology, fantasy.

Entre os anos de 2003 e 2006 trabalhei como professor de inglês e coordenador de atividades diversas relativas ao ensino e à aprendizagem de língua inglesa, no contexto de formação de professores de inglês como língua estrangeira no curso de Letras da Universidade Federal de São João del-Rei. No contexto específico de meu trabalho, a língua inglesa era obviamente objeto de debates corriqueiros em minha interlocução com alunos do curso de Letras da UFSJ. A esse respeito, interessou-me o fato de

Professor de Língua Inglesa e Linguística Aplicada da Universidade Federal de São João del-Rei. Doutorando em Linguística pelo Instituto de Estudos da Linguagem da Unicamp. E-mail: edgasparini@ig.com.br 


\section{Revista Solta a Voz, v. 20, n. 1}

que a língua inglesa parecia organizar todo um campo de significação. Havia certa exuberância de sentidos sobre a língua inglesa, o que despertou meu interesse. Essa riqueza de sentidos, que se desdobrava em minhas relaçóes com alunos do curso de Letras, mostrava um caráter de reprodução insistente de sentidos.

Em novembro de 2005, submeti ao Departamento de Letras, Artes e Cultura da UFSJ o projeto de pesquisa "Representaçóes acerca da língua inglesa (como língua estrangeira) no discurso de alunos do curso de letras da Universidade Federal de São João del-Rei” (cf. Gasparini, 2005). Amparada na Análise do Discurso de Michel Pêcheux, a pesquisa tinha o objetivo de investigar como os alunos representavam a língua inglesa em seu discurso. Para cumprir esse objetivo, propus-me a analisar depoimentos escritos por alunos de Letras, nos quais estes dissertaram brevemente acerca da língua inglesa.

Alguns elementos da Análise do Discurso foram importantes para a elaboraçáo do projeto de pesquisa. $\mathrm{Na}$ abordagem da ideologia articulada por Pêcheux, a teoria althusseriana da interpelação ocupou, a partir de certo momento da obra de Pêcheux (cf. Pêcheux, 1988), um lugar de destaque. De acordo com Louis Althusser (1998, p. 96), "toda ideologia interpela os indivíduos concretos enquanto sujeitos concretos". Através do mecanismo da interpelação, a ideologia constitui o sujeito de uma formação social, ou seja, o sujeito implicado numa estrutura de relaçôes sociais. Nesse sentido, todo "indivíduo" é desde sempre "sujeito", sujeito que emerge na interpelação ideológica. Uma passagem de Aparelhos ideológicos de Estado (Althusser, 1998) me parece fundamental para situar a abordagem da ideologia e do discurso articulada por Pêcheux. Segundo Althusser (idem, p. 94-95),

tanto para vocês como para mim, a categoria de sujeito é uma "evidência" primeira (as evidências são sempre primeiras): está claro que vocês, como eu, somos sujeitos (livres, morais, etc.). Como todas as evidências, inclusive as que fazem com que uma palavra "designe uma coisa" ou "possua um significado" (portanto inclusive as evidências da "transparência" da linguagem), a evidência de que vocês e eu somos sujeitos [...] é um efeito ideológico, o efeito ideológico elementar. Este é aliás o efeito característico da ideologia - impor (sem parecer fazê-lo, uma vez que se tratam de "evidências") as evidências como evidências, que não podemos deixar de reconhecer e diante das quais, inevitável e naturalmente, exclamamos (em voz alta, ou no "silêncio da consciência"): "é evidente! é exatamente isso! é verdade!". 
A abordagem do discurso realizada por Michel Pêcheux (1988) coloca em relevo a concretização do "efeito característico da ideologia" (Althusser, 1998, p. 94) na materialidade da língua e destaca a noção de discurso como lugar onde se estabelece uma relação entre língua e ideologia. No discurso - efeito de sentido entre locutores - a emergência das significaçōes é marcada pela imposição das "evidências como evidências" (idem, p. 94). Segundo Pêcheux (1988, p. 160), "é a ideologia que fornece as evidências pelas quais 'todo mundo sabe' o que é um soldado, um operário, um patrão, uma fábrica, uma greve, etc., evidências que fazem com que uma palavra ou um enunciado 'queiram dizer o que realmente dizem". O sujeito como origem evidente do sentido é, nessa perspectiva, efeito do funcionamento da ideologia.

No mencionado projeto de pesquisa, propus-me a analisar depoimentos escritos por alunos de Letras, nos quais estes dissertaram brevemente acerca da língua inglesa. Pretendi abordar o que havia sido identificado como um campo de significaçáo no nível dos efeitos da ideologia - mecanismo de produção de evidências (cf. Pêcheux, 1988) - na materialidade linguística do discurso. Para tanto, seria necessário partir de um corpus, de um lugar a partir do qual seria possível identificar, na materialidade da língua, os efeitos de evidência exercidos pela ideologia na configuração de "representaçôes" acerca da língua inglesa.

Vale lembrar que, na perspectiva da Análise do Discurso articulada por Pêcheux $(1997,1988)$, a língua é considerada como "fundo invariante" (Pêcheux, 1997, p. 75), como "base comum de processos discursivos diferenciados" (Pêcheux, 1988, p. 91). Segundo Pêcheux (idem, p. 91),

o sistema da língua é, de fato, o mesmo para o materialista e para o idealista, para o revolucionário e para o reacionário, para aquele que dispóe de um conhecimento dado e para aquele que náo dispóe desse conhecimento. Entretanto, não se pode concluir, a partir disso, que esses diversos personagens tenham o mesmo discurso: a língua se apresenta, assim, como a base comum de processos discursivos diferenciados [...].

Ao opor base lingüistica e processo discursivo, inicialmente estamos pretendendo destacar que [...] todo sistema lingüístico, enquanto conjunto de estruturas fonológicas, morfológicas e sintáticas, é dotado de uma autonomia relativa que o submete a leis internas, as quais constituem, precisamente, o objeto da Lingüística. 


\section{Revista Solta a Voz, v. 20, n. 1}

De acordo com Pêcheux (1997, p. 75), os processos discursivos se desenrolam então sobre o "fundo invariante" da língua, dotado de uma "autonomia relativa" (Pêcheux, 1988, p. 91), base comum sobre a qual o discurso exerce efeitos de sentido. A partir da dicotomia instaurada por Saussure (1974) entre a língua e a fala, Pêcheux (1997, p. 74) faz intervir a dimensão do discurso como um "nível intermediário" entre a língua e a fala, que aponta para o registro da "particularidade" (idem, p. 74). Eis a "mudança de terreno" (idem, p. 73) efetuada por Pêcheux, que faz intervir um elemento externo à região da Linguística: o jogo de posiçóes constitutivo de uma formação social, que se configura como condiçôes de produção do discurso. Nessa direção, é possível afirmar que Pêcheux atualiza o deslocamento efetuado por Saussure da função da língua (de expressar sentido) em direção ao seu funcionamento. Entretanto, ao destacar o "nível intermediário" (Pêcheux, 1997, p. 74) do discurso, trata-se, para Pêcheux, de colocar em relevo um funcionamento que é regido por condiçóes externas ao sistema. Entendo que ao propor como explicativo do funcionamento da língua um elemento exterior a esta - o jogo de forças constitutivo de uma formação social Pêcheux náo leva em conta um elemento importante para o retorno à obra de Sigmund Freud realizado por Jacques Lacan, qual seja, a noção de valor no Curso de lingüistica geral (cf. Saussure, 1974). Na "mudança de terreno" realizada por Pêcheux $(1997$, p. 73 ) se esboça uma exclusão do sujeito que, para Jacques Lacan, advém da remissão necessária de um significante a outro significante. A noção de língua como "base comum de processos discursivos" configura um ponto de exclusão do sujeito do inconsciente na teoria da Análise do Discurso desenvolvida por Michel Pêcheux (1997, 1988).

Por ora, menciono aqui alguns segmentos que, recortados dos depoimentos dos alunos, foram destacados numa análise inicial dos textos acerca da língua inglesa (cf. Gasparini, 2006). Todos os destaques em itálico são meus:

\section{S (segmento) 1}

[...] essa língua tornou-se universal fazendo com que os países interajam entre si.

Por isso, é importante e fundamental a aprendizagem desse idioma. 


\section{S2}

Saber inglês hoje em dia é fundamental para termos uma boa comunicação com as pessoas.

A língua inglesa invadiu os meios de comunicação de tal forma que se as pessoas não se adaptam são excluídas.

\section{S3}

A língua inglesa é de fundamental importância na sociedade atual. O mundo globalizado e a quebra de barreiras promovidas pela Internet nos aproxima ainda mais de outras culturas. Daí, a necessidade de conhecer o inglês, tê-lo como mais uma ferramenta de interaçâo.

\section{S4}

A língua inglesa possui uma grande importância na vida de qualquer pessoa, pois nos dias atuais tem sido a nossa segunda língua.

Para se obter um emprego é de fundamental importância o conhecimento do inglês, pois ele está presente no nosso cotidiano desde um aparelho de som a um filme.

\section{S5}

A língua inglesa em qualquer que seja a ocasião é de fundamental importância, indispensável em qualquer situação.

$\mathrm{O}$ inglês, assim como outros idiomas, abre diversas oportunidades inexistentes sem o conhecimento pelo menos básico principalmente do inglês, língua mais utilizada e imprescindivel.

\section{S6}

Está mais que provado que o inglês é fundamental.

S7

Vivemos a era da Internet, com muitas informaçóes em inglês, se você domina a lingua, consegue se sair bem.

\section{S8}

Fazer inglês é uma necessidade global para quem deseja ao menos ser respeitado.

\section{S9}

Desde que comecei a aprendê-la sinto-me muito mais ligada ao mundo. Quem não tenta aprender, não sabe o que está perdendo! 
S10

[a língua inglesa] É importante por diminuir a distância entre as pessoas e possibilitar uma interação entre elas.

S11

A língua inglesa se expandiu pela forte imposição dos EUA em relação aos outros países, o que de certa forma não é algo totalmente natural, mas não podemos ignorar o quanto isso facilitou o relacionamento entre pessoas de nacionalidades diferentes.

S12

O que dizer sobre uma língua que é capaz de unir pessoas de países completamente diferentes? Não só países, mas de um modo geral, culturas diferentes.

\section{S13}

O inglês hoje deixou de ser uma língua complementar para se tornar um requisito obrigatório em qualquer currículo. Isso porque o mundo todo adotou esta como a língua universal. [...] Ter uma segunda língua torna a pessoa mais comunicável. Não ter o inglês como opção pode ser um grande incômodo.

$[\ldots]$

[...] Se o mundo aceita o inglês como língua universal, seria coerente que todos pudessem aprendê-la.

É preciso, ainda, um maior empenho neste projeto de familiarizar o mundo com esta língua estrangeira. Para que isso não seja apenas um objetivo e se torne a realidade táo sonhada.

Amparado na Análise do Discurso articulada por Pêcheux (1997, 1988), propus-me a identificar a forma pela qual se configurou, na materialidade linguística dos depoimentos, uma determinada representação acerca da língua inglesa como língua estrangeira. Como pode ser visto, a qualificação da língua inglesa como "importante" e "fundamental" abunda nos recortes aqui trazidos. Os depoimentos não cessam de destacar a "grande importância" que o inglês possui no mundo contemporâneo, na vida de "qualquer pessoa" (cf. S4). Assim, temos em S5 a afirmação de que o inglês "é de fundamental importância, indispensável em qualquer situação". E, a esse respeito, parece não haver dúvidas, pois "está mais do que provado" que o inglês é fundamental (cf. S6) para qualquer pessoa. 
Esta "importância comprovada" da língua inglesa está em conexão com a idéia de que "para se obter um emprego é de fundamental importância o conhecimento do inglês" (cf. S4), pois ele é um "requisito obrigatório em qualquer currículo" (cf. S13).

$\mathrm{Na}$ análise realizada, destaquei também o fato de que a língua inglesa é representada como uma espécie de garantia, a garantia de uma "boa comunicação" (S2) com o outro, pois ela nos "aproxima ainda mais de outras culturas" (S3), diminuindo a "distância entre as pessoas" e possibilitando uma "interação entre elas" (cf. S10). Nessa direção, o inglês "facilita" o relacionamento entre pessoas de nacionalidades diferentes (S11), pois é supostamente capaz de "unir" (S12) povos de países diversos. A análise da materialidade linguística constitutiva dos depoimentos indicou também que se, por um lado, saber a língua inglesa possibilita uma "interação" com o mundo globalizado, não sabê-la leva a uma "exclusão" (S2), o que pode ser causa de um "grande incômodo" (cf. S13).

Portanto, na materialidade linguística dos depoimentos escritos pelos alunos, a língua inglesa se configura como evidentemente "fundamental", "indispensável": ela garante sucesso profissional e união entre os povos (enquanto não sabê-la leva à "exclusão" e ao "incômodo"): tesouro de valor inestimável ("quem não tenta aprender [a língua inglesa], não sabe o que está perdendo!" - cf. S9), que possibilitaria uma inserção no mundo globalizado e uma relação harmoniosa com o outro, livre de impasses. Considero particularmente significativa a afirmação de que a aprendizagem da língua inglesa por "todos" possibilitaria atingir "a realidade tâo sonhada!" (S13). Entretanto, caberia perguntar: de que sonho se trata aqui?

A esse respeito, gostaria de mencionar um comercial de televisão de uma escola de idiomas: a propaganda apresenta um jovem pulando alegremente no mar, após o que a câmera se volta para um aviso no píer, escrito em inglês e espanhol: "Perigo: tubarôes!". Nesse ponto, pergunto: o que poderia ser táo terrível quanto (ou mesmo mais terrível que) a perspectiva de ter o corpo devorado por tubaróes? Do "sonho" de falar inglês como garantia de uma "maior comunicabilidade" com o outro, teríamos chegado ao pesadelo? Ao invés de identificar os efeitos da ideologia na materialidade da língua através da análise de um corpus, seria mais frutífero se interrogar sobre o seu esteio, o ponto em que sustenta um campo ideológico?

Em suas consideraçóes acerca da Análise do Discurso articulada por Michel Pêcheux, Slavoj Žižek (1996, p. 17) reconhece que "um dos estrata- 


\section{Revista Solta a Voz, v. 20, n. 1}

gemas fundamentais da ideologia é a referência a alguma evidência - 'Olhe, você pode ver por si mesmo como são as coisas!' ou 'Deixe os fatos falarem por si”’. Entretanto, é o próprio Žižek (1992, p. 154) que afirma que

não basta denunciar o caráter "artificial" da experiência ideológica, demonstrar como o objeto apreendido pela ideologia como "natural" e "dado" é uma construção discursiva, o resultado de uma rede de sobredeterminação simbólica, e não basta situar o texto ideológico em seu contexto, tornar visíveis seus limites necessariamente desprezados.

A partir de sua "leitura política" do grafo do desejo assim como construído por Jacques Lacan, Žižek (1992, p. 121) indica "a deficiência crucial" das abordagens da ideologia derivadas da teoria althusseriana da interpelação, indicando que "para além da interpelação, existe o quadrado do desejo da fantasia, da falta no Outro e da pulsão que vibra em torno de um insustentável mais-gozar" (idem, p. 21).

Fundamental para uma aproximação da visada de Žižek acerca da ideologia é a questão da identificação, em sua vertente imaginária e simbólica, assim como elaborada por Lacan. Para Žižek (1992, p. 70), é na articulação fundamental entre a identificação especular, imaginária, e a identificação simbólica - "identificação com o traço unário, com um significante no Outro, com uma Causa que transcenda a vivência imaginária e faça parte da ordem simbólica" - que se constitui o mecanismo de inserção do sujeito num dado campo sócio-simbólico. "O problema”, diz Žižek (1992, p. 109), "reside apenas no fato de que essa 'quadratura do círculo' da interpelação, esse movimento circular entre a identificação simbólica e a identificação imaginária, nunca se dá sem um certo resto". Seguindo as indicaçóes de Žižek (1992, p. 121), pode-se dizer que o mecanismo da interpelação não exerce seus efeitos sem que se produza um resto não interpelável, marca da ordem simbólica como ordem inconsistente, "sendo a fantasia uma tentativa de ultrapassar, de mascarar essa inconsistência, esse furo no Outro".

Para Žižek (1992), a inconsistência da ordem simbólica é o esteio fundamental do funcionamento da ideologia. É a partir do funcionamento paradoxal da fantasia, no tamponamento e sustentação da falta no grande Outro, que Žižek articula sua abordagem da ideologia. Permitindo "escapar da situação insuportável e sem saída em que o Outro quer algo de nós, mas na qual, ao mesmo tempo, somos incapazes de traduzir esse desejo do 
Outro numa interpelação positiva, numa missão com que possamos nos identificar" (idem, p. 112-113), a ideologia na condição de fantasia estrutura a realidade social.

No que se refere à ideologia, não se trata de um mascaramento da "realidade efetiva"; num certo sentido, é mesmo o contrário: a própria ideologia revela a realidade, há uma ilusão, um erro que rege a efetividade de um campo social. Se for de mascaramento que se trata, o que a ideologia mascara não é a realidade, mas antes a falta, o vazio em torno do qual se estrutura o edifício social. A partir da idéia de que o campo social é marcado por uma inconsistência, por uma clivagem antagônica estrutural, não integrável na ordem simbólica, Žižek (1992, p. 123) nos diz que "o que está em jogo na fantasia ideológico-social é construir uma visão de sociedade que exista, de uma sociedade que náo seja antagonicamente dividida, uma sociedade em que a relação entre suas diferentes partes seja orgânica e complementar". Se numa perspectiva marxista a ideologia é abordada como apagamento da realidade efetiva, como "olhar parcial", na perspectiva desenvolvida por Žižek (1991, p. 151) "a ideologia denuncia, antes, uma totalidade que quer apagar os vestígios de sua impossibilidade". Nesse sentido, a "crítica da ideologia" pode subverter um edifício ideológico denunciando "dentre seus elementos, aquele que ocupa o lugar de sua própria impossibilidade" (idem, p. 151). Nessa direção, se o "método discursivo" de crítica da ideologia busca uma espécie de "desconstrução" da evidência de sentido a partir de uma análise do texto, na abordagem proposta por Žižek (1992, p. 122) busca-se articular como, para além do campo da significaçáo, mas como esteio mesmo desse campo, "uma ideologia implica, manipula e produz um gozo pré-ideológico estruturado na fantasia".

A ideologia corresponde a um tamponamento paradoxal, pois tampona o que náo pode ser tamponado: tampona e sustenta o furo não representável no cerne mesmo da ordem simbólica, "o núcleo real que retorna como o mesmo através das diversas historicizações / simbolizações” (Žižek, 1991, p. 152). Aliás, é essa a condição que garante que um edifício ideológico contemple a própria possibilidade de subversão desse campo. A esse respeito, seria possível sustentar que as articulaçóes de Althusser sobre a ideologia se configuram como lugar onde a interpelação efetivamente funciona, sem deixar resto? Resto que, na perspectiva elaborada por Žižek, é esteio da ideologia e da própria possibilidade de ruptura em relação a um edifício ideológico? 
10 Revista Solta a Voz, v. 20, n. 1

Segundo Žižek (1991, p. 155),

O desafio da cena fantasística é realizar a relação sexual, deslumbrar-nos, com sua presença fascinante, sobre o impossível da relação sexual - e é a mesma coisa com a fantasia "social", com o constructo fantasístico em que se baseia um campo ideológico: em última análise, estamos sempre lidando com a fantasia de uma relação de classe, com a utopia de uma relaçáo harmoniosa, orgânica, complementar entre as partes da totalidade social.

Se, de acordo com Žižek, a fantasia ideológica mascara o antagonismo social, compondo a sociedade como um todo harmônico, então pergunto: a perspectiva de um mundo no qual a língua inglesa é garantia da "união entre os povos" revela, se seguirmos as indicaçóes de Žižek, um caráter eminentemente ideológico? O engodo da "aproximação" e da "integração" entre os povos graças à língua inglesa elide um impasse fundamental, o núcleo real de não relação como elemento irredutível do corpo social? Poderia o "sonho da união entre os povos" (através da língua inglesa) ser tomado como uma construçấo ideológica na qual a língua inglesa, na medida em que organiza essa construção, encarna sua própria impossibilidade? A língua inglesa como "língua ideal para a comunicação" anuncia o próprio ponto em que a perspectiva de uma "uniâo entre os povos" é marcada por um impossível, está fadada ao fracasso? As mesmas questóes poderiam ser levantadas acerca da promessa de "sucesso profissional" e de um "bem-viver" na sociedade contemporânea, supostamente garantidos pela aprendizagem da língua inglesa. $\mathrm{O}$ que está em jogo na perspectiva de uma inserção "bem sucedida" na sociedade graças à língua inglesa corresponde à elisão do impasse colocado em cena pelo núcleo de não relação que atravessa toda formação social?

Retomo outro elemento da argumentação de Žižek (1991) acerca da ideologia. O autor (idem, p. 167-168) menciona uma espécie de "curtocircuito" constitutivo do funcionamento de um campo ideológico, relacionado pelo autor a uma espécie de escolha forçada: "cedo ou tarde, tropeça-se no ponto em que o sujeito é confrontado com essa escolha impossível - ele pode optar livremente entre 'pró' e 'contra', mas, desde que escolha mal, que se decida pelo 'contra', ele perde a liberdade de escolha”. É em relação a esse ponto que podemos abordar o comercial de televisão mencionado anteriormente. Acaso o que o comercial coloca em cena não tem o caráter de 
imposição de uma escolha forçada entre "a bolsa ou a vida" (cf. Lacan, 1985, p. 201)? Acaso o que o comercial atualiza não é a perspectiva segundo a qual, em nossa sociedade democrática e liberal, podemos ou náo falar inglês, mas se não falamos estamos cruelmente excluídos dela? Nesse sentido, a injunção ao consumo da língua na condição de mercadoria assume um caráter inesperadamente terrível: o comercial de televisão adquire um caráter mais cruel do que a perspectiva de ter o corpo devorado por tubaróes.

É nessa direção que podemos entender a importância fundamental atribuída à língua inglesa nos depoimentos analisados. As garantias supostamente oferecidas pela língua inglesa (garante emprego e um lugar na sociedade globalizada) colocam em cena uma promessa de gozo, a satisfação garantida, sem perda, o que aponta para uma perspectiva segundo a qual supostamente estaríamos liberados de ter de assumir os riscos, causados pelo desejo, consonantes à situaçáo de sermos seres marcados pela falta... Promessa da satisfação garantida que, entretanto, está fadada ao insucesso: as formaçóes do inconsciente - lugares onde o sujeito desponta em sua singularidade - são o testemunho de que uma interpelação comporta necessariamente um caráter falho, de que uma interpelação não exerce seus efeitos sem que produza um resto não simbolizável. Afinal, pergunta Žižek (1992, p. 111), "que é a histeria senão, precisamente, o efeito e o testemunho de uma interpelação malograda?”.

\section{REFERÊNCIAS}

ALTHUSSER, L. Aparelhos ideológicos de Estado. Rio de Janeiro: Ediçōes Graal, 1998.

GASPARINI, E. N. "Representaçóes acerca da língua inglesa (como língua estrangeira) no discurso de alunos do curso de Letras da Universidade Federal de São João del-Rei”. Projeto de pesquisa submetido ao Departamento de Letras, Artes e Cultura da Universidade Federal de Sáo João del-Rei em novembro de 2005. Não publicado.

"Sentidos de Língua Inglesa no Discurso". Comunicação apresentada no Seminário de Pesquisa em Análise do Discurso: percursos de Análise do Discurso no Brasil, realizado no Instituto de Letras e Lingüística da Universidade Federal de Uberlândia no período de 31 de maio a 02 de junho de 2006. Não publicado. 
LACAN, J. O Seminário, livro 11, Os quatro conceitos fundamentais da psicanálise. 2. ed. Rio de Janeiro: Jorge Zahar Editor, 1985.

PÊCHEUX, M. Análise automática do discurso. In: GADET, F; HAK, T. (Orgs.). Por uma análise automática do discurso - uma introduçáo à obra de Michel Pêcheux. Campinas: Editora da Unicamp, 1997. p. 61-161.

. Semântica e discurso - uma crítica à afirmação do óbvio. Campinas: Editora da Unicamp, 1988.

SAUSSURE, F. Curso de lingüistica geral. 6. ed. São Paulo: Editora Cultrix, 1974.

ŽIŽEK, S. Eles não sabem o que fazem: o sublime objeto da ideologia. Rio de Janeiro: Jorge Zahar Editor, 1992.

. O espectro da ideologia. In: ŽIŽEK, S. (Org.) Um mapa da ideologia. Rio de Janeiro: Contraponto Editora, 1996. p. 7-38.

. O mais sublime dos histéricos: Hegel com Lacan. Rio de Janeiro: Jorge Zahar Editor, 1991.

Recebido em: 15 out. 2008 Aceito em: 11 fev. 2009 